\title{
Vaginal infections and contraception Results of a patient questionnaire
}

\author{
Harriet Wallace', Michelle Loftus-Keeling ${ }^{1}$, Nadia Ekong1', Jonathan Ross ${ }^{2}$, Catherine Armitage ${ }^{3}$, Janet Wilson'
} ${ }^{1}$ Leeds Sexual Health, ${ }^{2}$ University Hospital Birmingham NHS Foundation Trust, ${ }^{3}$ Leeds Student Medical Practice

\section{Background}

Bacterial vaginosis (BV) and vulvovaginal candida are common problems amongst females using contraception. Associations between BV/candida and different contraception are described but evidence is conflicting $(1,2)$.

\section{$\operatorname{Aim}(\mathbf{s}) /$ objectives}

1. Establish knowledge of BV/candida amongst contraceptive users.

2. Assess whether future research on $\mathrm{BV} /$ candida and contraception would be of interest to patients.

\section{Methods}

Surveys were distributed to females at Leeds Sexual Health, Umbrella sexual health clinic (Birmingham), and Leeds Student Medical Practice. Surveys were given out by staff not consulting with patients and responses were anonymous.

Age, reason for visit and current contraception use was asked, in addition to the following questions. Answers were multiple choice with space for additional comments.

The survey sheet contained background information including:

Symptoms of BV and candida, available treatments Recurrence possibility

What is already known about contraception and BV candida

\section{Questions posed:}

Had you heard of BV or candida before today?

Would you be interested in outcomes of research looking at the links between BV and candida and different contraceptive methods?

What outcomes in research into BV and candida and contraception would be important to you?

If a contraceptive method was found to increase your chance of developing BV or candida, would you still consider STARTING that method?

If a contraceptive method was found to increase your chance of developing BV or candida, would you CHANGE from that method if you had NO SYMPTOMS of $B V$ or candida

If the contraceptive method you were using was found to increase your chance of developing BV or candida would you change from that method if you got SYMPTOMS?

\section{Conclusions}

This survey shows there is lay interest in further research into associations between vaginal infections and contraception. Many women remain unaware of BV and candida, and knowledge in this area would influence contraceptive choices and method changes.

A recent publication by the $\mathrm{FSRH}$ highlighted ten priorities for future contraception research; this subject would fall into Priority 2, ascertaining clear information for women on risk of side effects from hormonal contraception (3).

\section{Results}

298 women completed the survey. The following table illustrates reason for attendance on the day of the survey:

\begin{tabular}{|l|l|l|l|}
\hline Reason for attendance & GP & $\begin{array}{l}\text { Sexual } \\
\text { health }\end{array}$ & $\begin{array}{l}\text { Total } \\
(\mathbf{n = 2 9 8})\end{array}$ \\
\hline Contraception & 32 & 125 & 157 \\
\hline STI testing/treatment & 5 & 32 & 37 \\
\hline Not contraception / STI related & 96 & 8 & 104
\end{tabular}

There was an even spread of ages comparing those attending for contraception vs other attendances (Fig 1). $32 \%$ of contraception attenders were using a LARC.

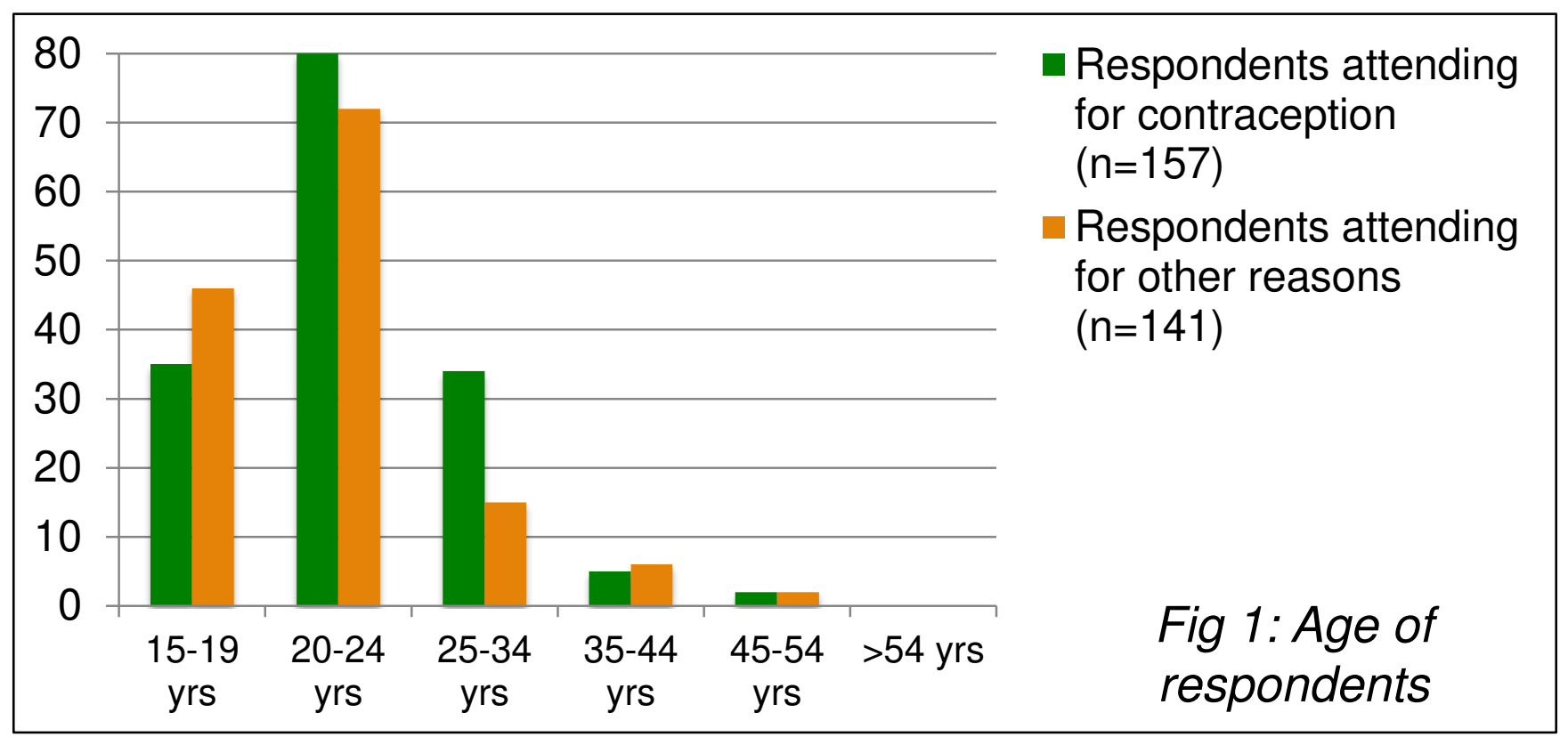

Baseline knowledge of vaginal infections increased with age: overall $40 \%$ of respondents attending for contraception had heard of BV and 39\% candida, but in $<20$ years just $26 \%$ had heard of $\mathrm{BV}$ and $17 \%$ candida.

A large number of contraception respondents expressed an interest in future research in this area, no matter if they had heard of BV/candida or not (Fig 2). Fig 3 shows the main area of interest as a link between contraception type and developing vaginal infections (all respondents).
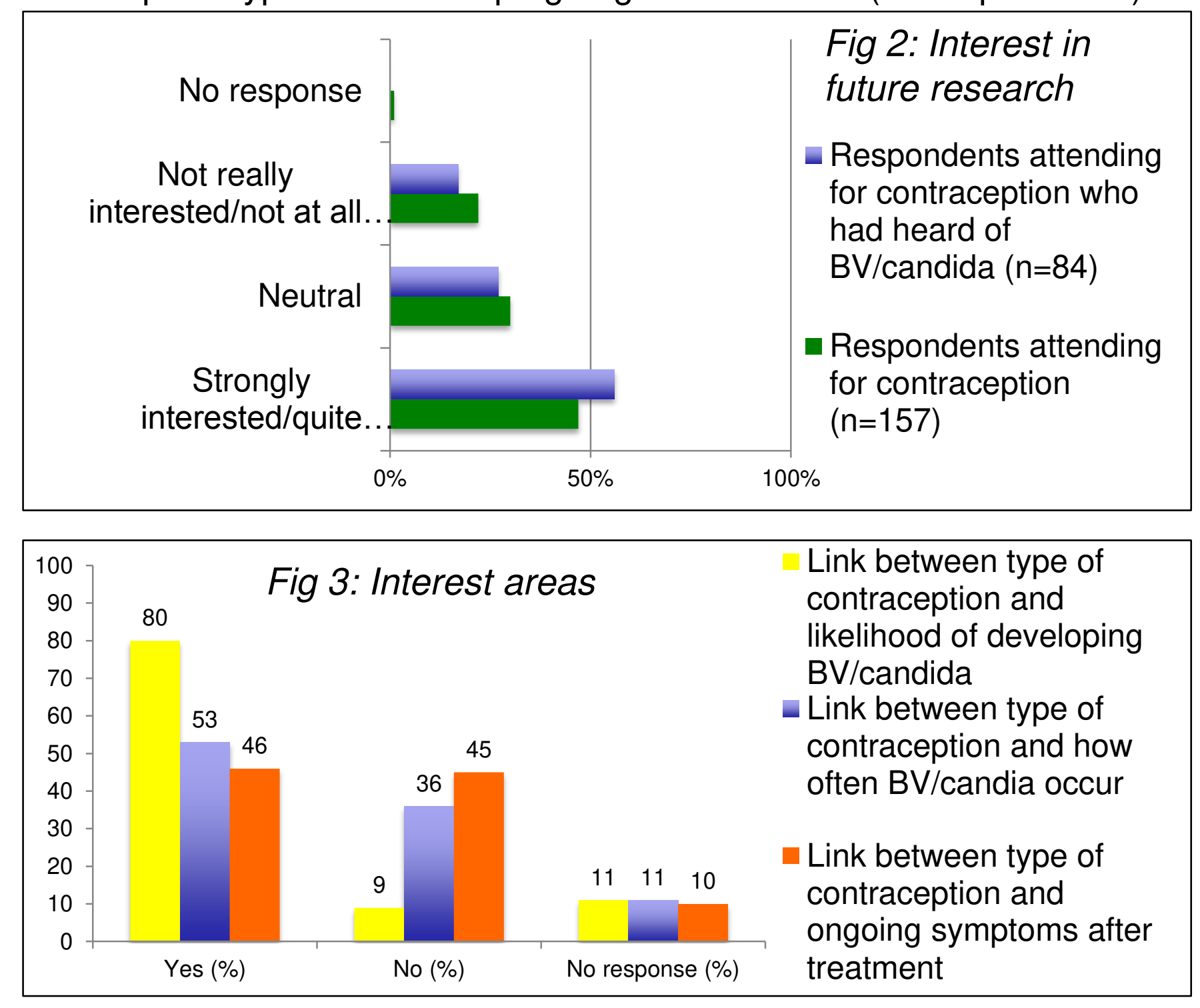

$81 \%$ of respondents attending for contraception stated they would change a method if it was proven to increase the chance if developing $\mathrm{BV} /$ candida and they developed that infection. $65 \%$ would not consider starting a method if a link to increased vaginal infections was proven.

1. Madden T, Grentzer JM, Secura GM et al. Risk of bacterial vaginosis in users of the intrauterine device: A longitudinal study. Sex Transm Dis 2012;39:217222

2. Avonts D, Sercu M, Heyerick $P$ et al. Incidence of uncomplicated genital infections in women using oral contraception or an intrauterine device: A prospective study. Sex Transm Dis 1990;17:23-29 